\title{
Research of Sliding Mode Control in Electro-optical Tracking System
}

\author{
GUO Zipeng, XIE Chaoming \\ Hubei Polytechnic Institute \\ Mechanical and Electrical Engineering School \\ xiaogan, china \\ gzp2004@tom.com
}

\author{
XIAO Yongjun* \\ Hubei engineering university \\ School of physics and electronic information \\ engineering \\ xiaogan, china \\ xiaoyongjun2003@126.com
}

\begin{abstract}
Space optical communication, the electro-optical tracking system is a typical nonlinear system. However, the angular accuracy should be better than a few micro-radians to meet the requirement of the communication link construction between two terminals. To get more control precision, the mathematic model of the coarse pointing system is founded, and sliding mode variable structure controller with approach law is designed. Finally, the simulation is done separately for a typical PID controller and the variable structure controller. Simulation results are showed that the sliding mode control can finely control the attitude of coarse pointing system, and can get higher precision by contrasted to the conventional PID controller.
\end{abstract}

Keywords- free-spce communication; sliding mode control; simulation; electro-optical tracking system

\section{INTRODUCTION}

It's known that laser communication is one of the promising systems for the future space inter-satellite or inter-orbit communication network because of its high security and high bit rate data in recent years ${ }^{[1 \sim 2]}$. Contrast to conventional radio frequency systems, the laser communication offers many advantages. There are, however, many challenges to construct the communication link. One is that received laser power is limited and varied because of receiver's sensitivity and atmosphere effect due to atmospheric turbulence and absorption or scattering of particles. Another matter that faces space communication is transmit laser beam must use extremely narrow beam divergence of several micro radians because of the distance between the satellites is far with over $3600 \mathrm{~km}$, so the ATP system must have extremely precision to control a transmitting and receiving laser beam with in angular accuracy better than a few micro radians ${ }^{[3 \sim 5]}$. To meet the requirement of the latter faced by space communication, we should find much better control method to get high precision.

As an important part of ATP system, the coarse pointing system is a typical electro-optical tracking system. In recent years, much attention has been paid to the control method of electro-optical tracking system in domestic and overseas researchers, however, each system need different control method. As it is known that Variable structure control with sliding mode, which is commonly known as sliding mode control (SMC), is a nonlinear control strategy that is well known for its robust characteristics ${ }^{[6 \sim 7]}$.

In this paper, the SMC method, which is often used in controlling incompletely modeled or uncertain systems, is used to the coarsing pointing system, compared to PID control methods. In section 2 , the mathematical model for servo motor is detailed. In section 3, the theory of sliding mode control is discussed, based on this principle, the design of SMC controller for coarsing pointing system of space communication is described. In section 4, comparisons are made between different control methods through digital simulation. At last, some conclusions are drawn.

\section{MODEL OF ELECTRO-OPTICAL TRACKING SYSTEM}

Generally, the servo motor, as the executer of the electro-optical tracking system for space communication, is a brushless DC torque motor (BLDC). Because it has many advantages, such as high efficiencies, high torque to inertia ratios, greater speed capabilities, low audible capabilities and lower EMI characteristic et al.

The dynamic model ${ }^{[8 \sim 9]}$ for servo motor is shown in fig 1. The same developed model is used for simulation.

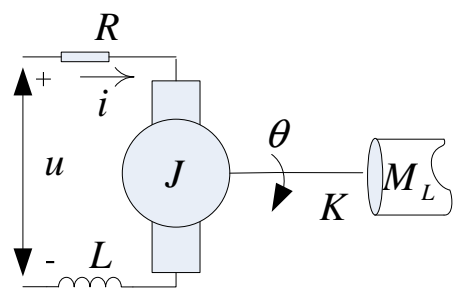

Fig.1 Schematic diagram for motor

The voltage equations given below are referred to general reference frame.

$$
\left\{\begin{array}{l}
R i+L \frac{d i}{d t}+K_{e} \frac{d q}{d t}=u \\
J \frac{d^{2} q}{d t^{2}}+D \frac{d q}{d t}+K q=M-M_{f} \\
M=K_{T} i
\end{array}\right.
$$

Where: $u$ is armature voltage of motor, $R$ is Armature resistance, $L$ is Armature inductance, $i$ is Armature 
current, $K_{e}$ is Motor back EMF coefficient, $\theta$ is Output angle of motor, $J$ is Inertia of motors, $D$ is Viscous damping coefficient of load, $K$ is Stiffness of replacement spring, $M$ is Electro-magnetic torque, $M_{f}$ is Torque of load, $K_{T}$ is Electro-magnetic torque constant.

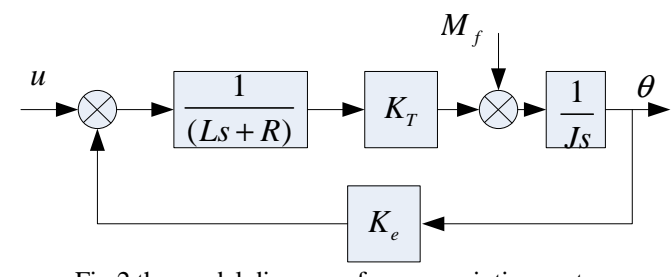

Fig.2 the model diagram of coarse pointing system

Use Laplace transformation to formula (1), an ideal model diagram we get on the basis of ignoring of some consideration, is shown in figure 2. Based on this diagram, the transformation function of the control system is the formula (2), and this transformation function is used in next simulations.

$$
\frac{\theta(s)}{u(s)}=\frac{K_{T}}{(L s+R) J s+K_{T} K_{e}}
$$

\section{THE DESIGN OF SLIDING MODE CONTROLLER}

Sliding mode control is fundamentally a consequence of discontinuous control. As for typical nonlinear system, the linear networks used before did not bring enough compensation to use high gains required to get parametric insensitivity. So sliding mode can be design and be not related to the parametric disturbance of object, with some good characters of high robust and fast response ${ }^{[10 \sim 15]}$.

\section{A. Sliding motion and its reachability condition}

As for a control system:

$$
x(k+1)=A x(k)+B u(k) x \in R^{n}, u \in R
$$

and exist a switch surface:

$$
S=S(X)=S\left(x_{1}, x_{2}, \cdots, x_{n}\right)=0
$$

The state space is divided into two part: $S>0$ and $S<0$. If a proper switch function $S(X)$ and a control signal $u$ exist, all trajectories are directed toward this surface (regardless of which side of the surface they are) and sliding along the surface.

It drives the trajectories to the switching surface and maintains it on this surface once it has been reached. The local attractivity of the sliding surface can be expressed by the condition

$$
\begin{aligned}
& \lim _{s \rightarrow 0^{+}} \frac{\partial S}{\partial x}<0 \text { And } \lim _{s \rightarrow 0^{-}} \frac{\partial S}{\partial x}>0 \\
& \text { Or, in a more concise way, } \\
& S(k+1) S(k)<0
\end{aligned}
$$

\section{B. Design of sliding mode variable structure controller}

Usually, exponential approach law is commonly used to the design of sliding mode controller. For a discrete system, exponential Approach Law is

$$
\frac{s(k+1)-s(k)}{T}=-\xi \operatorname{sgn} s(k)-k s(k)
$$

Where $T$ is the sample period.

As for the switch surface:

$$
s(k)=c x(k)
$$

We can get the parameter $c$ by using spline collocation method or optimal control method, so the formula (7)

$$
\begin{aligned}
& s(k+1)=c x(k+1)=c A x(k)+c b u(k) \\
& =(1-k T) s(k)-\xi T \operatorname{sgn} s(k)
\end{aligned}
$$

Thus, the control signal

$$
u=-(c b)^{-1}[c A x(k)+(k T-1) s(k)+\xi T \operatorname{sgn} s(k)]
$$

\section{DIGITAL SIMULATION AND ANALYSIS}

For the servo motor of the electro-optical tracking system, some parameters are as follows: $R=2.60 \Omega$, $L=26 m H \quad, \quad K_{e}=0.047 \mathrm{v} / \mathrm{r} \cdot \mathrm{min}^{-1} \quad$, $J=148 \mathrm{~kg} \cdot \mathrm{m}^{2} \times 10^{-5}, D=2.4047(N \cdot \mathrm{m}) / \mathrm{rad}$, $K_{T}=0.047 \mathrm{v} / \mathrm{r} \cdot \mathrm{min}^{-1}, K=0.0047(N \cdot \mathrm{m}) / \mathrm{rad}$. So we can get the detailed transmission function.

If the $r(k)=0.5^{*} \sin (6 k \pi)+0.8 \sin (14 k \pi)$, and $T=0.001 s, c=10, \xi=5, k=30$, the initial state $x[0]=[-0.5,0.5]$, the simulation of typical PID control method and sliding mode control is done to compare the performance. The tracking curve of PID is shown in figure 3, and the tracking curve of sliding mode control is shown in figure 4, the tracking performance of sliding mode control is better compared to PID control.

The phase locus for sliding mode control is shown in figure 5; the real motion near the surface can be seen as the superposition of a "slow" movement, along the surface, however some obvious chattering is also exist.

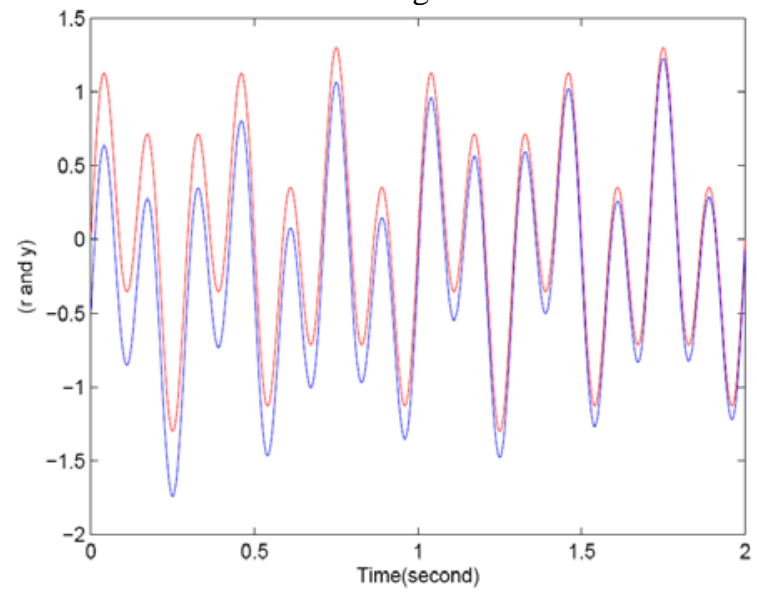

Fig.3 tracking curve for PID control method 
(The blue line is input $r(k)$, and the red line is tracking curve)

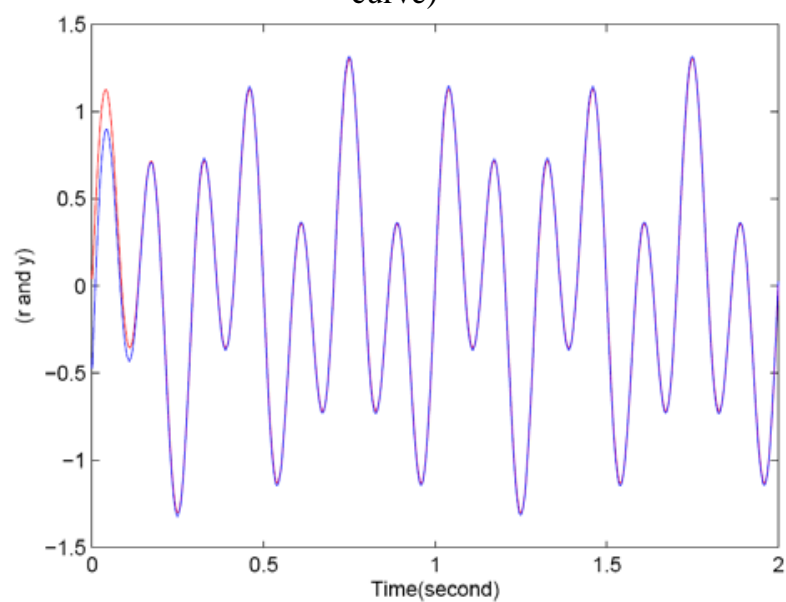

Fig.4 tracking curve for sliding mode control

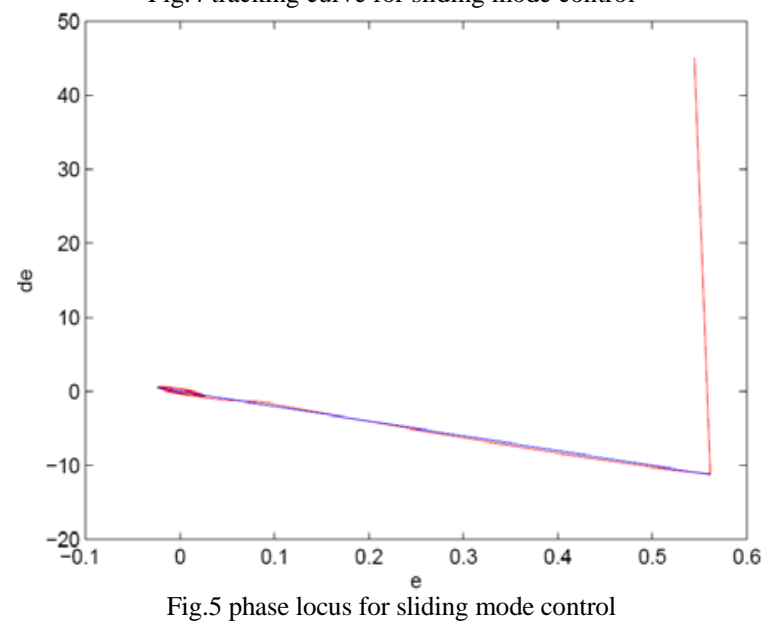

V. CONCLUSIONS

In space optical communication, as the transmission distance is often too long faced with limited transmission power, the acceptance angle of the receiver is very small. The ATP system needs much more precision to control the transmission and receive terminal. The coarsing pointing system of ATP system, however, is a typical nonlinear system; conventional control method can not satisfy the requirement, so we attempt to use sliding mode control to the coarse pointing system. We also find the tracking performance of sliding mode control is better compared to PID control by digital simulation, but some obvious chattering also exists in sliding mode control. So how to weaken or even eliminate the chattering is our research trend in the next work. Perhaps single control method is not get the high precision, so compound control which combines two or much more method should be paid more attention in future work.

\section{REFERENCES}

[1] M. Bilgi and M. Yuksel, "Multi-Element Free-Space-Optical Spherical Structures with Intermittent Connectivity Patterns", Proceedings of IEEE INFOCOM Student Workshop, Phoenix, AZ, April 2008.

[2] T. Araki, et al., "Present and Future of Optical Intersatellite Communication Research", Free-Space Laser Communication Technologies VI 1994, pp. 2.

[3] K. J. Held and J. D. Barry, "Precision pointing and tracking between satellite-borne optical systems,” Opt. Eng. 27(4), pp. 325-333, 1988.

[4] M. Witting, K. van Holts, D. E. L. Tunbridge, and H. C. Vermeulen, "In-orbit measurement of microaccelerations of ESA's communication satellite OLYMPUS,” Proc. SPIE 1218, pp. 205-214, 1990.

[5] T. T. Nielsen, "Pointing, Acquisition and Tracking system for the Free Space Laser Communication System,

[6] SILEX”, Free-Space Laser Communication Technologies VII 1995, SPIE, pp. 194.

[7] Emelyanov V.S and FedotovaA.L, "Design of a static tracking systems with variable structure", Automation and Remote Control, pp.1223-1235No.10, 1962

[8] XIE Lei, "Research on Control Theory based on Variable Structure Control Strategy for Flight Simulator", Nanjing University of Aeronautics and Astronautics, February 2006.

[9] LI ZhongHua, "control system for ship-borne optoelectronic platform based on v variable structure control strategy”, harbin engineering university, march,2008

[10] R. A. DeCarlo, S. H. Zak, and G. P. Matthews, "Variable structure control of nonlinear multivariable systems: A tutorial," Proc. IEEE, vol. 76, no. 3, pp. 212-232, 1988.

[11] Jium-Ming Lin, Po-Kuang Chang, Applying intelligent fuzzy control to reduce hysteresis effect of force actuator in a SPM, WSEAS Transactions on Systems and Control, v.4 n.7, p.271-285, July 2009

[12] L. Yu, J.-P. Barbot, D. Boutat, D. Benmerzouk, "Observability normal forms for a class of switched systems with zeno phenomena”, Proceedings of the 2009 conference on American Control Conference, p.1766-1771, June 10-12, 2009, St. Louis, Missouri, USA

[13] R. A. DeCarlo, S. H. Zak, and G. P. Matthews, "Variable structurecontrol of nonlinear multivariable systems: A tutorial,” Proc. IEEE, vol.76, no. 3, pp. 212-232, 1988.

[14] R. A. DeCarlo, S. H. Zak, and G. P. Matthews, "Variable structure control of nonlinear multivariable systems: A tutorial," Proc. IEEE, vol. 76, no. 3, pp. 212-232, 1988.

[15] R. A. DeCarlo, S. H. Zak, and G. P. Matthews, "Variable structure control of nonlinear multivariable systems: A tutorial,” Proc. IEEE, vol. 76, no. 3, pp. 212-232, 1988. 